\title{
Incidence and Prevention of Ischemic Stroke following Myocardial Infarction: Review of Current Literature
}

\author{
Monisha Dutta ${ }^{a}$ Elias Hanna $^{b}$ Pranab Das $^{c}$ Steven R. Steinhubl ${ }^{c}$ \\ a Department of Neurology, ${ }^{b}$ Department of Internal Medicine and ' $L i n d a$ and Jack Gill Heart Institute, \\ University of Kentucky, Lexington, Ky., USA
}

Key Words

Myocardial infarction $\cdot$ Stroke $\cdot$ Anti-platelet therapy

\begin{abstract}
Myocardial infarction is the leading cause of death today. With the fast progress in pharmacotherapy and revascularization technology, outcomes following a myocardial infarction have become very favorable. While most of the complications from a myocardial infarction can be adequately managed, thus leading to reduced mortality, stroke following a myocardial infarction remains a challenge even today, and can lead to potentially devastating complications. We discuss the incidence, pathophysiology, and management options of non-hemorrhagic stroke following a myocardial infarction.

Copyright $\odot 2006$ S. Karger AG, Basel
\end{abstract}

Stroke, either hemorrhagic or non-hemorrhagic (ischemic) is one of the leading causes of mortality and significant disability worldwide [1]. Although newer pharmacological and mechanical interventions after a myocardial infarction (MI) have been successful in improving survival from an MI, stroke remains a catastrophic complication of ST-elevation MI (STEMI) or non-ST-elevation acute coronary syndrome (NSTE-ACS), with a mor- tality rate of up to $60 \%$ at one year $[2,3]$. Mortality from ischemic stroke can be up to $10-20 \%$, and even higher with hemorrhagic stroke. When compared with a matched cohort of stroke patients without a preceding MI, patients with stroke following an MI had increased in-hospital and long-term mortality with in-hospital mortality of $30 \%$, more acute and more extensive deficits, and greater residual deficits at 6 months [4]. In a recent communitybased study [5] of stroke incidence after an MI, there was a 44-fold increase in risk of stroke within the first month after the MI, with the risk persisting even at 3 years after the MI. Therapeutic advancements for MI have not changed the rate of mortality from post-MI stroke as evidenced by over a decade of follow-up in this study.

\section{Incidence of Stroke during the Post-MI Period}

With nearly 1,000,000 individuals diagnosed with an acute MI annually in the United States, the population at risk is substantial [6]. The incidence of an ischemic stroke within a month after a STEMI has been found to be $\sim 2 \%$ [7-9] and up to $1 \%$ within 90 days after NSTE-ACS [10]. About 1 in 40 patients over age 65 may suffer from an ischemic stroke after an MI within 6 months, but the level of risk for an individual patient can be better determined based on the presence or absence of several clinical

\section{KARGER}

Fax +41613061234 E-Mail karger@karger.ch www.karger.com
(C) 2006 S. Karger AG, Basel

1015-9770/06/0226-0331\$23.50/0

Accessible online at:

www.karger.com/ced
Steven R. Steinhubl, MD

900 S. Limestone St

326 C.T. Wethington Bldg

Lexington, KY 40536 (USA)

Tel. +1 859323 8040, Fax +1 859323 6475, E-Mail steinhubl@uky.edu 


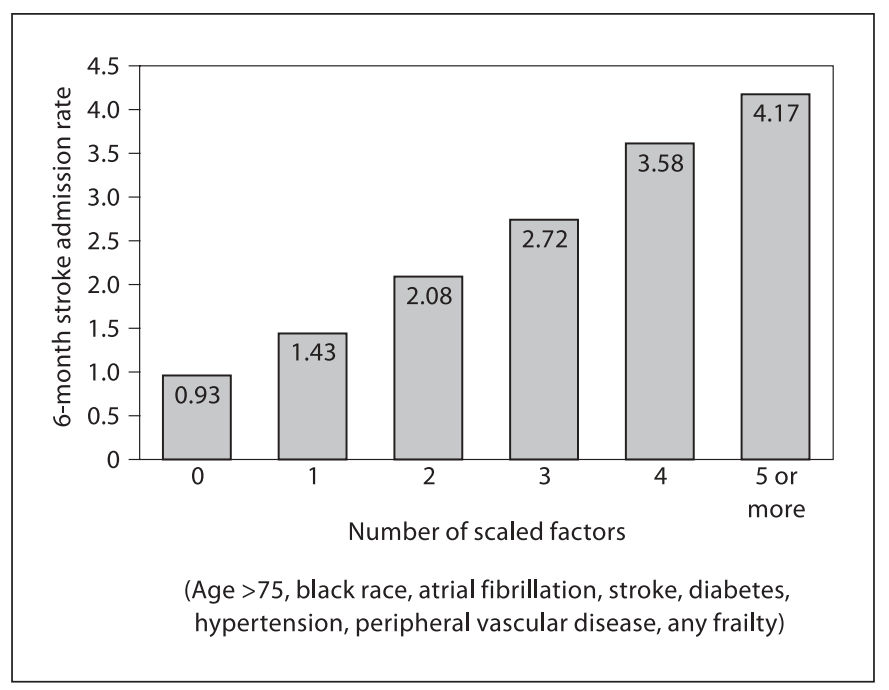

Fig. 1. Predictors of stroke during the 6 months following a myocardial infarction [adapted from ref. 11].

factors (fig. 1) [11]. Most ischemic strokes occur after $48 \mathrm{~h}$ of STEMI in fibrinolytic-treated patients, and the first 28 days after a STEMI remains the most vulnerable period for an ischemic stroke (fig. 2) [12].

\section{Risk Factors of Stroke after MI}

Atrial fibrillation (AF), whether new or chronic, is the single most important risk factor for post-MI stroke. AF can occur in up to $20 \%$ of patients following a STEMI and is associated with a significant increase in risk for an inhospital stroke and increase in both in-hospital and shortterm mortality [13]. Along with AF, prior stroke, age $>75$, black race, peripheral vascular disease, diabetes, hypertension, any frailty, and no aspirin on discharge are independent predictors of an ischemic stroke [11]. Advanced Killip class (class II or above), AF/flutter (new or chronic) and cardiac procedures (cardiac catheterizations and coronary artery bypass graft surgery - CABG) have also been found to be in-hospital predictors of ischemic stroke [14].

While some studies had identified anterior wall MI as one of the predictors of post-MI stroke, several other larger studies with longer follow-up have disputed this association $[15,16]$. Clearly the degree of myocardial damage as measured by the post-MI left ventricular ejection fraction (LVEF) is associated with stroke risk. An 18\% relative increase in risk for every $5 \%$ decrease in LVEF (rela-

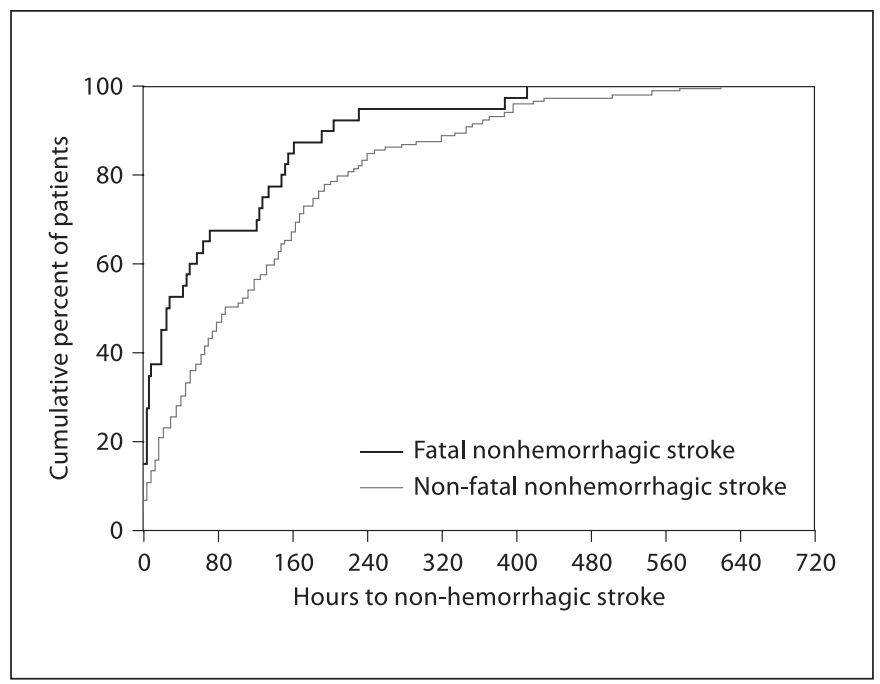

Fig. 2. Timing of non-hemorrhagic stroke following a STEMI [adapted from ref. 14].

tive risk of stroke 1.86 versus those with $\mathrm{EF}>35 \%$, $\mathrm{p}=$ 0.01 ) has been demonstrated [17].

\section{Pathogenesis of Stroke after an MI}

Historically, the view has been held that myocardial injury, particularly from a larger infarct such as an anterior infarct, predisposes to formation of left ventricular mural thrombus (LVMT) due to flow characteristics in the left ventricle. This LVMT then becomes a potential source of embolic events, with systemic anticoagulation therefore being protective [15]. LVMT is most likely to occur by 2 weeks after an MI in $0.6-3.7 \%$ of patients, a rate which is substantially lower than the earlier reported incidence of $20-56 \%$ [18]. Adjunctive pharmacological therapy with antiplatelet agents and antithrombotic agents, along with early revascularization, might have contributed to the reduction in LVMT formation [19].

An alternative mechanism may also play a role in the pathogenesis of stroke after an MI. Increased coagulation activity during an ACS, persisting at least up to 6 months, can potentially lead to increased thrombosis and subsequent thromboembolic events including stroke [20]. Emboli may come from the aorta or carotid arteries, or even from the left atrium or left ventricle. Catecholamine activation following an MI may also lead to enhanced platelet aggregation and thrombus generation. 
A diffuse and heightened state of inflammation persists following an ACS in the coronary vasculature [21, 22]. The circulatory inflammatory cytokines [23] may incite a cascade of events in the cerebral circulation. As evidence of this, complex and presumably unstable carotid plaques are found to be common in patients with ACS (42\% with unstable angina versus $8 \%$ with stable angina, $\mathrm{p}=0.002$ ) [24]. This may contribute to plaque rupture and subsequent thrombus formation in the cerebral circulation.

With the rapid progress in the technology of mechanical revascularization and development of improved adjunctive pharmacological agents, percutaneous coronary intervention (PCI) has become the standard of care for patients with an ACS, and a higher percentage of patients, are now undergoing cardiac catheterizations and revascularization when indicated. While early revascularization has been shown to improve cardiovascular outcomes in high-risk ACS patients, its effect on the incidence of stroke is concerning. GUSTO-1 [14] data showed that coronary angiography and coronary artery bypass graft surgery (CABG) were associated with increased stroke risk. Similarly, analysis of the OASIS [25] registry found that patients from countries with higher rates of invasive cardiac procedures (CABG and coronary angiography) suffered from increased risk of stroke at 6 months $(\mathrm{p}=0.004)$. However, in the more recent analysis of OASIS patients (>18,000 patients with NSTE-ACS) [3], only CABG was associated with significant risk of stroke and there was no significant risk of stroke among patients undergoing PCI compared to those who had no invasive procedures.

The type of revascularization therapy in the setting of an ACS can influence the risk of stroke. In a review of 23 randomized trials of primary angioplasty versus fibrinolytic therapy for acute MI, the incidence of stroke was found to be lower with PCI than with fibrinolytic therapy (total stroke, $0.9 \%$ with PCI vs. $2 \%$ with fibrinolysis, $\mathrm{p}=$ 0.0004 and hemorrhagic stroke, $0.05 \%$ with PCI vs. $1.1 \%$ with fibrinolysis, $\mathrm{p}<0.0001$ ) [26]. However, in the secondary analyses of two recent prospective randomized trials of acute MI, the incidence of stroke did not differ between the primary PCI group and the fibrinolytic groups $[27,28]$. Table 1 summarizes the stroke incidence based on the reperfusion therapy after an MI in the VALIANT trial [29]. The 6-month incidence of stroke among NSTE-ACS patients undergoing PCI appears to be lower compared with patients undergoing CABG surgery, and delayed CABG ( $\geq 14$ days post-MI) appears to cause fewer cases of stroke compared with early CABG $(<14$ days after an MI) [3].

Incidence and Prevention of Ischemic

Stroke following Myocardial Infarction
Table 1. Reperfusion therapy and risk of stroke (hemorrhagic and non-hemorrhagic) [adapted from ref. 27]

\begin{tabular}{ll}
\hline Reperfusion strategy & $\begin{array}{l}\text { Incidence } \\
\text { of stroke, \% }\end{array}$ \\
\hline Thrombolytic therapy & $1.5^{*}$ \\
Primary PCI & $1.1^{*}$ \\
Both thrombolytics and PCI & 1.1 \\
Thrombolytics \pm PCI & 1.3 \\
No reperfusion therapy & 1.5 \\
\hline
\end{tabular}

* No statistically significant difference between primary PCI and thrombolytic therapy. $\mathrm{PCI}=$ Percutaneous coronary intervention.

\section{The Role of Antithrombotic Therapy in the Prevention of Post-MI Stroke}

\section{Antiplatelet Therapy}

Acute aspirin therapy is the single most effective antiplatelet therapy in the prevention of ischemic stroke after an MI. In ISIS-2, aspirin use not only significantly reduced the incidence of cardiovascular death but also the occurrence of both total stroke and non-hemorrhagic stroke, either alone or in combination with streptokinase [30]. It is now universal practice for all MI patients to receive at least $81 \mathrm{mg}$ aspirin daily unless the patient has true aspirin allergy. With the increasing use of PCI with stenting in the treatment of patients with an MI, use of the platelet ADPreceptor antagonist clopidogrel, typically in combination with aspirin, has become more widespread. Data from the large, randomized, prospective CURE trial [32] of longterm clopidogrel in addition to aspirin following a NSTEACS, found only non-significant trends in reduction of stroke. This minimal benefit was hampered by a significant excess in major bleeding with the combination therapy. Similarly, in the MATCH trial [61] comparing clopidogrel with aspirin versus clopidogrel alone in patients with high stroke risks, the dual therapy was responsible for a significant excess of bleeding complications.

The role of dual antiplatelet therapy with aspirin and clopidogrel (DT) in STEMI has been studied in two recently reported placebo-controlled randomized trials. The CLARITY-TIMI 28 trial randomized 3,491 patients with STEMI receiving primary thrombolytic therapy and aspirin to clopidogrel or matching placebo [33]. Clopidogrel reduced the composite of death, recurrent $\mathrm{MI}$, or urgent

Cerebrovasc Dis 2006;22:331-339 
Table 2. Antiplatelet therapy and stroke in post-MI trials

\begin{tabular}{|c|c|c|c|c|c|c|c|c|c|}
\hline \multirow[t]{2}{*}{ Trial and year } & \multirow[t]{2}{*}{ Patients } & \multirow{2}{*}{$\begin{array}{l}\text { Primary } \\
\text { indication }\end{array}$} & \multirow[t]{2}{*}{ Primary end point } & \multicolumn{3}{|l|}{ Stroke } & \multicolumn{3}{|c|}{ Major bleeding } \\
\hline & & & & aspirin & $\begin{array}{l}\text { aspirin }+ \\
\text { clopidogrel }\end{array}$ & $\mathrm{p}$ & aspirin & $\begin{array}{l}\text { aspirin+ } \\
\text { clopidogrel }\end{array}$ & $\mathrm{p}$ \\
\hline $\begin{array}{l}\text { CURE [32] } \\
2001\end{array}$ & 12,562 & NSTE-ACS & $\begin{array}{l}\text { CV death } \\
\text { Non fatal MI } \\
\text { Stroke }\end{array}$ & 1.4 & 1.2 & NS & 2.2 & 2.8 & 0.02 \\
\hline $\begin{array}{l}\text { CLARITY [33] } \\
2005\end{array}$ & 3,491 & STEMI & $\begin{array}{l}\text { Occluded IRA, } \\
\text { death, recurrent MI }\end{array}$ & 1.7 & 0.9 & 0.052 & 1.7 & 1.9 & 0.8 \\
\hline $\begin{array}{l}\text { COMMIT [35] } \\
2005\end{array}$ & 45,852 & $\begin{array}{l}\text { STEMI }(93 \%) \\
\text { NSTE-ACS (7\%) }\end{array}$ & $\begin{array}{l}\text { Death, reinfarction, } \\
\text { stroke }\end{array}$ & 1.1 & 0.9 & 0.11 & 0.59 & 0.58 & 0.59 \\
\hline
\end{tabular}

IRA = Infarct-related artery; NSTE-ACS = non-ST-elevation acute coronary syndrome; STEMI = ST-segment elevation; MI = myocardial infarction.

revascularization at 30 days by $20 \%$ compared with placebo and reduced the odds of stroke by $46 \%(\mathrm{p}=0.052)$. The benefit of clopidogrel was independent of the site of MI and caused no increase in major bleeding. In the PCI-CLARITY trial [34], a pre-specified subgroup of CLARITY-TIMI 28 participants undergoing PCI within 48-192 h of randomization, clopidogrel reduced the composite of death, $\mathrm{MI}$, and stroke by $46 \%$ at 30 days $(\mathrm{p}=0.008)$ and the rate of stroke by $68 \%$ at 30 days (OR $0.32,95 \%$ CI 0.1-1.01). The COMMIT-CCS2 trial [35] randomized 45,852 patients within $24 \mathrm{~h}$ of suspected acute MI onset to clopidogrel $75 \mathrm{mg}$ daily or matching placebo in addition to aspirin $162 \mathrm{mg}$ daily (93\% had ST-segment elevation or bundle branch block, and 7\% had ST-segment depression) for up to 4 weeks (mean 15 days). The primary outcome of the composite of death, re-infarction, or stroke favored clopidogrel with $9 \%$ relative risk reduction over placebo $(\mathrm{p}=0.002)$, and no significant excess risk (bleeding or hemorrhagic stroke) was noted with clopidogrel $(\mathrm{p}=0.59)$, or in patients aged older than 70 years, or in those given fibrinolytic therapy. Clopidogrel caused a non-significant $14 \%$ reduction in the risk of stroke $(0.9 \%$ with clopidogrel vs. $1.1 \%$ with placebo, $\mathrm{p}=0.11$ ). Table 2 summarizes the impact of antiplatelet therapy on stroke outcome after an MI. Figure 3 illustrates an algorithm in the management of chronic ischemic stroke for long-term prevention. However, for the acute phase of stroke, each case must be decided based on its clinical and radiological severity. Concomitant co-morbidities such as diabetes or pharmacotherapies such as warfarin or dual antiplatelet therapy with aspirin and clopidogrel should also be taken into consideration, as these conditions are associated with high likeli- hood of hemorrhagic conversion of an ischemic stroke. Dipyridamole and cilostazol, two other antiplatelet agents, are not indicated in ACS and LV dysfunction respectively, making their evaluation in post-MI stroke difficult.

\section{Anticoagulant Therapies}

Anticoagulants (such as heparins) are one of the cornerstones in the pharmacological treatment of ACS patients, and a rebound increase in thrombotic events can occur following cessation of these therapies [37]. Several post-MI warfarin-aspirin combination trials [38-42] have compared aspirin alone versus aspirin with low-dose warfarin (INR 2-3) vs. high-dose warfarin (INR >2.8) among patients after an MI (both NSTE-ACS and STEMI). While most of these trials have favored warfarin with aspirin or warfarin over aspirin alone in reduction of stroke, both the warfarin regimens caused more bleeding (table 3 ). Thus, warfarin at moderate dose with INR $2-3$ in addition to aspirin (75-162 $\mathrm{mg}$ ) appears to be more effective in reducing post-ACS stroke and major cardiovascular events compared with aspirin alone, but at the cost of some increase in major bleeding. All subsets of ACS patients (anterior versus non-anterior MI, and STEMI versus NSTEACS) appear to benefit from this combination.

\section{Optimal Antithrombotic Regimens in Special Circumstances}

\section{PCI following MI}

Dual antiplatelet therapy with aspirin and clopidogrel is now preferred to aspirin and systemic anticoagulation 
Table 3. Trials of aspirin and warfarin on stroke and major bleeding

\begin{tabular}{|c|c|c|c|c|c|c|c|c|c|c|c|}
\hline \multirow[t]{2}{*}{ Trial and year } & \multirow{2}{*}{$\begin{array}{l}\mathrm{Pa}- \\
\text { tients }\end{array}$} & \multirow{2}{*}{$\begin{array}{l}\text { Primary } \\
\text { indication }\end{array}$} & \multirow{2}{*}{$\begin{array}{l}\text { Primary } \\
\text { end point }\end{array}$} & \multicolumn{4}{|c|}{ Non-hemorrhagic stroke } & \multicolumn{4}{|c|}{ Major bleeding } \\
\hline & & & & $\begin{array}{l}\text { low } \\
\text { dose } \\
\text { Asa, \% }\end{array}$ & $\begin{array}{l}\text { Asa }+ \\
\text { warfarin } \\
\text { INR } 2-3, \%\end{array}$ & $\begin{array}{l}\text { high dose } \\
\text { warfarin } \\
\text { INR } 2.8-4.2, \%\end{array}$ & $\mathrm{p}$ & $\begin{array}{l}\text { low } \\
\text { dose } \\
\text { Asa, \% }\end{array}$ & $\begin{array}{l}\text { Asa }+ \\
\text { warfarin } \\
\text { INR 2-3, \% }\end{array}$ & $\begin{array}{l}\text { warfarin } \\
\text { INR } \\
2.8-4.2, \%\end{array}$ & p \\
\hline $\begin{array}{l}\text { LoWASA [42] } \\
2003\end{array}$ & 3,300 & AMI & $\begin{array}{l}\mathrm{CV} \text { death, re-infarction } \\
\text { and stroke }\end{array}$ & 5 & 3.4 & - & 0.016 & 1 & 2.2 & - & 0.0006 \\
\hline $\begin{array}{l}\text { HAMP }[41] \\
2002\end{array}$ & 5,059 & AMI & All causes of death & 3.5 & 3.1 & - & 0.52 & 0.72 & 1.28 & - & $<0.001$ \\
\hline $\begin{array}{l}\text { WARIS II [39] } \\
2002\end{array}$ & 3,630 & AMI & $\begin{array}{l}\text { Death, non-fatal } \\
\text { re-infarction, stroke }\end{array}$ & 0.88 & 0.47 & 0.47 & $0.03^{*}$ & 0.17 & 0.57 & 0.68 & $<0.001^{*}$ \\
\hline $\begin{array}{l}\text { ASPECT-2 [38] } \\
2002\end{array}$ & 999 & $\begin{array}{l}\text { AMI and } \\
\text { NSTEACS }\end{array}$ & MI, stroke, death & 1 & 0 & 0 & $\mathrm{NS}^{+}$ & 1 & 2 & 1 & $0.2^{+}$ \\
\hline $\begin{array}{l}\text { CARS }[40] \\
1997^{\mathrm{a}}\end{array}$ & 8,803 & AMI & $\begin{array}{l}\text { reinfarction, non-fatal } \\
\text { ischemic stroke, or } \\
\text { cardiovascular death }\end{array}$ & 0.58 & 1.1 & 0.8 & $\begin{array}{l}0.05^{* *} \\
0.16^{* * *}\end{array}$ & 1.5 & 1.7 & 2.0 & $\mathrm{NS}^{++}$ \\
\hline
\end{tabular}

Asa $=$ Aspirin; ${ }^{*} \mathrm{p}$ same for aspirin vs. combination and aspirin vs. warfarin; ${ }^{+} \mathrm{p}$ for aspirin vs. combination; ${ }^{*}$ p for aspirin vs. low dose warfarin and aspirin combination; ${ }^{* * *} \mathrm{p}$ for aspirin vs. high dose warfarin and aspirin combination; ${ }^{++} \mathrm{p}$ for aspirin vs. both combination groups.

a In CARS trial, low dose warfarin group had $1 \mathrm{mg}$ warfarin with $80 \mathrm{mg}$ aspirin (INR, median 1.05) and high dose warfarin group had $3 \mathrm{mg}$ warfarin with $80 \mathrm{mg}$ aspirin (median INR 1.5 at week I, 1.27 at week 4, and 1.19 at 6 months).

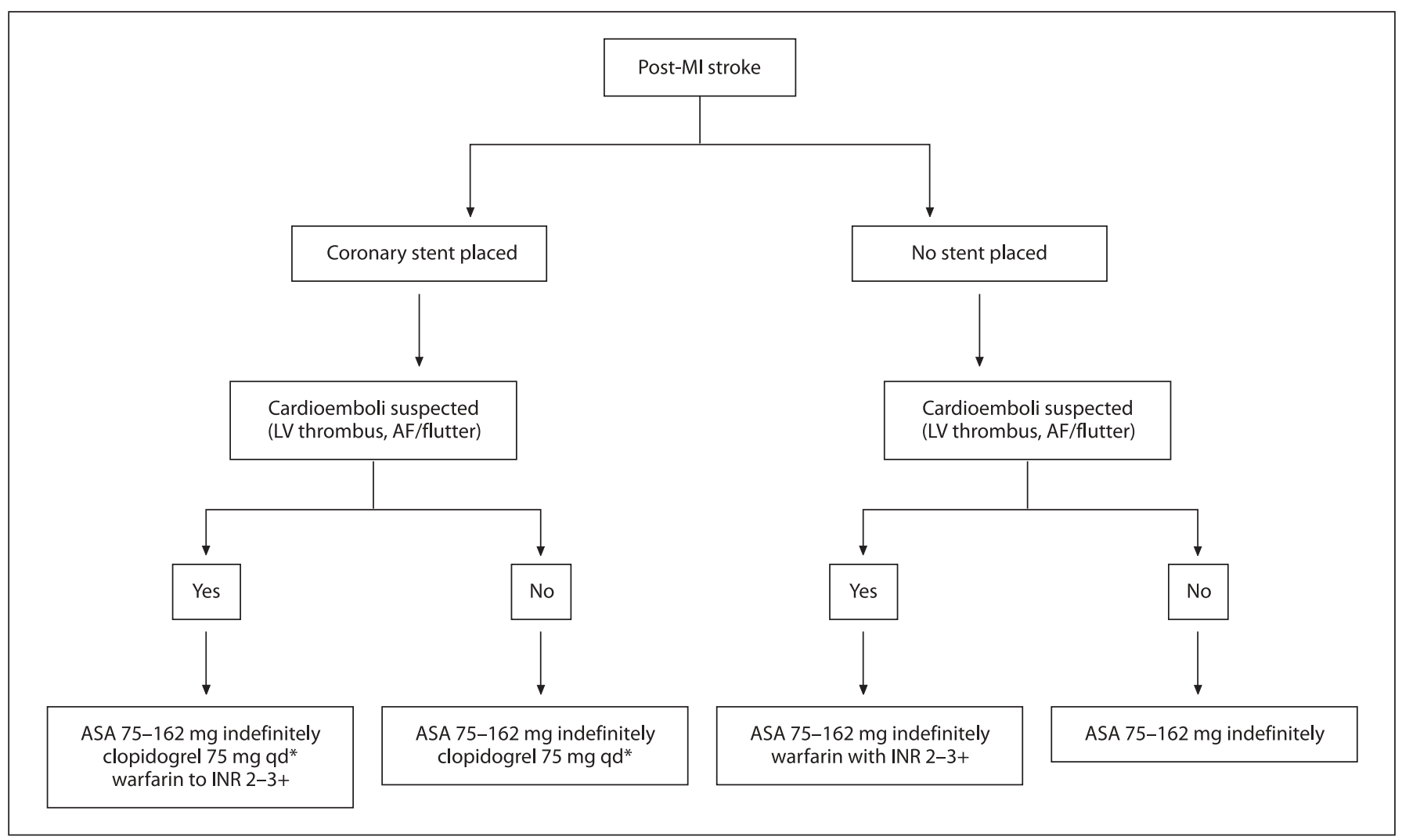

Fig. 3. Algorithm for management of post-MI stroke. * Clopidogrel $75 \mathrm{mg}$ daily for up to 1 month for bare metal stent, 3 months for sirolimus-eluting stent, and 6 months for paclitaxel-eluting stent. + Warfarin to INR 2-3 for 3 months for LMVT or akinetic segments and indefinitely for AF/flutter. 
Table 4. Predictors of major bleeding in AF [modified from ref. 36]

\begin{tabular}{llc}
\hline Risk level & Score & $\begin{array}{r}\text { Bleeding risk } \\
\text { at 48 months }\end{array}$ \\
\hline Low & 0 & $3 \%$ \\
Moderate & $1-2$ & $12 \%$ \\
High & $3-4$ & $53 \%$ \\
\hline
\end{tabular}

One point each for age $\geq 65$, history of stroke, history of gastrointestinal bleeding and any of the 4 co-morbidities e.g. recent $\mathrm{MI}=$ hematocrit $<30 \% ; \mathrm{DM}=\mathrm{Cr}$ $>1.5 \mathrm{mg} / \mathrm{dl}$.

with warfarin following PCI with a coronary stent [4345]. However, the continued need for oral anticoagulation for specific patients (e.g. AF, prosthetic heart valves, venous thromboembolism and LVMT) already on DT can be a problem, as the risk of bleeding from prolonged therapy with aspirin, clopidogrel and warfarin is poorly understood. Two retrospective studies $[46,47]$ have attempted to analyze the safety and efficacy of triple therapy and found higher rates of bleeding or need for transfusion. Another large population-based observational cohort study [48] from Canada studied 21,443 elderly survivors of acute MI over a 4-year period for any hospitalization for bleeding and found a trend toward increased bleeding with triple therapy.

Since the risk of stent thrombosis with bare metal stents (BMS) is highest in the first 1 to 2 weeks [49], it is reasonable that patients who require long-term warfarin should receive DT for 2 weeks followed by a single antiplatelet therapy; in addition, warfarin can be continued with close INR monitoring. However, drug-eluting stents are used more commonly than BMS today and for these stents the minimum safe duration of DT is at least 3-6 months.

\section{Atrial Fibrillation/Flutter}

AF after a STEMI occurs in up to $20 \%$ of patients and can cause increased in-hospital and long-term mortality, increased stroke with profound morbidity [50-52], and increased mortality from both sudden and non-sudden cardiac death [52]. Increased age, Killip class, magnitude of MI (as by increased CK), anterior MI, left ventricular dysfunction, hypertension, and hypotension are considered to be predictors of AF after an MI [53]. Congestive heart failure, age $>75$, hypertension, diabetes mellitus,
Table 5. Risk assessment of annual stroke rate with AF [modified from ref. 54]

\begin{tabular}{llll}
\hline $\begin{array}{l}\text { CHADS } \\
\text { score }\end{array}$ & $\begin{array}{l}\text { Yearly risk } \\
\text { of stroke, } \%\end{array}$ & $\begin{array}{l}\text { Stroke risk } \\
\text { level }\end{array}$ & $\begin{array}{l}\text { Warfarin } \\
\text { therapy }\end{array}$ \\
\hline 0 & 1.9 & low & no \\
1 & 2.8 & low & no \\
2 & 4.0 & moderate & yes \\
3 & 5.9 & moderate & yes \\
4 & 8.5 & high & yes \\
5 & 12.5 & high & yes \\
6 & 18.2 & high & yes \\
\hline
\end{tabular}

CHADS2 score (1 point each for congestive heart failure, hypertension, age $\geq 75$ and diabetes, and 2 points for prior history of TIA/CVA)

and prior TIA/stroke are associated with increased thromboembolic events among AF patients [54]. On the other hand, increased age, heart failure, hepatic or renal disease, first AF episode, warfarin use, and aspirin use are reported to increase the risk of major bleeding [55]. Table 4 describes a model to predict the risk of bleeding on warfarin therapy, and Table 5 depicts an annual risk assessment tool for stroke.

No consensus exists among experts in the use of triple therapy with aspirin, clopidogrel and warfarin in patients with AF. Both ACC/AHA/ESC guidelines for AF [56] and ACCP guidelines [57] recommend warfarin in patients with AF and an additional risk factor, e.g. coronary artery disease. The ACC/AHA STEMI guidelines [53] recommend warfarin in AF after an MI (Class I, Level of evidence A), whereas the ESC in their STEMI guidelines [58] made no definite recommendations for warfarin among patients with AF post-MI for lack of any definitive studies.

Findings from the ACTIVE-W trial [59] of more than 6,500 patients with AF and at least one additional stroke risk factor randomized to receive either warfarin or DT observed an absolute increase of $1.7 \%$ (equivalent to a $47 \%$ relative increase) in the primary end point of stroke, MI, embolism, and vascular death at 1 year with DT compared with warfarin $(p=0.0006)$. The incidence of stroke was significantly lower with warfarin than with DT (1.4\% with warfarin versus $2.4 \%$ with DT, $\mathrm{p}=0.0006$ ). Patients on warfarin who continued on warfarin did better than patients who had post-randomization cross-over. Warfarin is therefore superior to DT for prevention of vascular events in patients with AF. 
A Swedish prospective cohort study [60] evaluated discharge EKGs of 6,182 patients discharged after admission following an acute MI or AF on . Among these patients, $78 \%$ had AF on admission, $13 \%$ were older than 75 years, $29 \%$ received oral anticoagulation on discharge, $60 \%$ received aspirin with or without a theinopyridine, and $11 \%$ received neither. Aspirin or a thienopyridine was given to $26 \%$ of patients on anticoagulation therapy. The adjusted 30-day and 1-year mortality favored the oral anticoagulation cohort (OAC) compared to the antiplatelet cohort (Non-OAC) with 7\% absolute and 29\% relative risk reduction $(\mathrm{p}<0.001)$. New MI or strokes (ischemic and hemorrhagic) were more common causes of death among the non-OAC group. Bleeding complications were similar between $\mathrm{OAC}$ and non-OAC, but fatal and non-fatal ischemic stroke commonly occurred with non-OAC. The relative risk reduction of mortality at 1 year with $\mathrm{OAC}$ with aspirin versus non-OAC was $30 \%$ (95\% CI 0.55-0.90).

Thus, patients with MI and AF should definitely receive oral anticoagulation (INR 2-3) even if already on DT. Likewise, warfarin is not as effective as DT for the prevention of stent thrombosis, so if a patient develops AF following PCI and stenting, warfarin cannot be directly substituted for an antiplatelet agent. This leads to a significant dilemma as to how best to treat patients with strong indications for triple therapy. Ideally, for patients needing long-term warfarin, the placement of a DES should be avoided if at all possible. With use of a BMS, therapy can be minimized to aspirin and warfarin alone after as little as 1-2 weeks. When a DES is used it is difficult to comfortably hold antiplatelet therapies prior to 3-6 months after stenting.

\section{Conclusion}

Stroke remains a devastating complication following myocardial infarction. Since all current revascularization strategies for MI support the use of combination aspirin and clopidogrel in the weeks to months following MI, the primary question involves the risk and benefit of additional antithrombotic protection for the prevention and treatment of post-MI stroke. While the role of warfarin in several clinical scenarios such as atrial fibrillation and LV mural thrombus is clear, and warfarin is clearly superior to aspirin/clopidogrel combination in atrial fibrillation, triple therapy in the setting of coronary stenting thus places these patients at increased risk of bleeding. Patients with increased bleeding risk but needing continued anticoagulation should therefore receive triple therapy only with very close INR monitoring and only for the least possible period (1-2 weeks for bare metal stents) and then only aspirin and warfarin. Early treatment and revascularization, irrespective of method, is likely the best way to decrease the risk of a peri-MI stroke, with mechanical revascularization most reliable when it is available in a timely manner. If stable, patients needing surgical revascularization and at increased stroke risk, should preferably wait 14 days before the surgery to minimize the risk of thromboembolic stroke [3]. A prospective randomized trial comparing dual antiplatelet therapy to aspirin/warfarin or aspirin/clopidogrel/warfarin combination among patients with myocardial infarction may help solve this puzzle.

\section{Acknowledgement}

Ms. Donna Gilbreath for her excellent editorial assistance.

\section{References}

1 Rothwell PM, Coull AJ, Silver LE, et al: Population-based study of event-rate, incidence, case fatality, and mortality for all acute vascular events in all arterial territories. Lancet 2005;366:1773-1783.

2 Tanne D, Gottlieb S, Hod H, et al: For the Secondary Prevention Reinfarction Israeli Nifedipine Trial (SPRINT) and Israeli Thrombolytic Survey Groups. Incidence and mortality from early stroke associated myocardial infarction in the prethrombolytic and thrombolytic era. J Am Coll Cardiol 1997;30:1484-1490.
3 Cronin L, Mehta SR, Zhao F, et al: Stroke in relation to cardiac procedures in patients with non-ST-elevation acute coronary syndrome. A study involving $>18,000$ patients. Circulation 2001:104:269-274.

-4 Mooe T, Olofsson BO, Stegmayr B: Ischemic stroke: impact of a recent myocardial infarction. Stroke 1999;30:997-1001.

5 Witt BJ, Brown RD, Jacobson SJ, et al: A community-based study of stroke incidence after myocardial infarction. Ann Intern Med 2005;143:785-792.

6 Heart disease and stroke statistics - 2005 update: American Heart Association. Available at www.americanheart.org
7 Fibrinolytic Therapy Trialists' Collaborative Group: Overview of early mortality and major morbidity results from all randomized trials of more than 1000 patients. Lancet 1994;343:311-322.

8 Becker RC, Burns M, Gore JM, et al: Early assessment and in-hospital management of patients with acute myocardial infarction at increased risk for adverse outcome: a nationwide perspective of current clinical practice. Am Heart J 1998;135:786-796.

$\checkmark 9$ Wienbergen H, Schiele R, Gitt AK, et al: Incidence, risk factors, and clinical outcome of stroke after acute myocardial infarction in clinical practice. Am J Cardiol 2001;87:782785 . 
10 Kassem-Moussa H, Mahaffey KW, Graffagnino $\mathrm{C}$, et al: Incidence and characteristics of stroke during 90-day follow-up in patients stabilized after an acute coronary syndrome. Am Heart J 2004;148:439-446.

-11 Lichtman JH, Krumholz HM, Wang Y, Radford M, Brass LM: Risks and predictors of stroke after myocardial infarction among the elderly. Results from the co-operative cardiovascular project. Circulation 2002; 105:1082-1087.

-12 Mooe T, Eriksson P, Stegmayr B: Ischemic stroke after acute myocardial infarction: a population-based study. Stroke 1997;28: 762-767.

13 Crenshaw BS, Ward SR, Granger CB, et al: Atrial fibrillation in the setting of acute myocardial infarction: the GUSTO-I experience. J Am Coll Cardiol 1997;30:406-413.

14 Mahaffey KW, Granger CB, Sloan MA, et al: Risk factors for in-hospital nonhemorrhagic stroke in patients with acute myocardial infarction treated with thrombolysis. Results from GUSTO-1. Circulation 1998;97:757764.

15 Vaitkus PT, Barnathan ES: Embolic potential, prevention, and management of mural thrombus complicating anterior myocardial infarction: a meta-analysis. J Am Coll Cardiol 1993;22:1004-1009.

-16 Bodenheimer MM, Sauer D, Shareef B, et al: Relation between myocardial infarct location and stroke. J Am Coll Cardiol 1994;24: 61-66.

17 Loh E, St John Sutton M, Wun CC, et al: Ventricular dysfunction and the risk of stroke after myocardial infarction. N Engl J Med 1997;336:251-257.

18 Greaves SC, Zhi G, Lee RT, et al: Incidence and natural history of left ventricular thrombus following anterior wall acute myocardial infarction. Am J Cardiol 1997;80:442-448.

$\checkmark 19$ Motro M, Barbash GI, Hod H, et al: Incidence of left ventricular thrombi formation after thrombolytic therapy with recombinant tissue plasminogen activator, heparin, and aspirin in patients with acute myocardial infarction. Am Heart J 1991;122:23-26.

20 Merlini PA, Bauer KA, Oltrona L, et al: Persistent activation of coagulation mechanism in unstable angina and myocardial infarction. Circulation 1994;90:61-68.

-21 Buffon A, Biasucci LM, Liuzzo G, et al: Widespread coronary inflammation in unstable angina. N Engl J Med 2002;347:5-12.

-22 Mauriello A, Sangiorgi G, Fratoni S, et al: Diffuse and active inflammation occurs in both vulnerable and stable plaques of the entire coronary tree: a histopathologic study of patients dying of acute myocardial infarction. J Am Coll Cardiol 2005;45:1585-1593.

23 Neumann FJ, Ott I, Gawaz M, et al: Cardiac release of cytokines and inflammatory response in acute myocardial infarction. Circulation 1995;92:748-755.
24 Lombardo A, Biasucci LM, Lanza GA, et al: Inflammation as a possible link between coronary and carotid plaque instability. Circulation 2004;109:3158-3163.

25 Yusuf S, Flather M, Pogue J, et al: Variations between countries in invasive cardiac procedures and outcomes in patients with suspected unstable angina or myocardial infarction without initial ST elevation. OASIS Registry investigators. Lancet 1998;352:507-514.

26 Keeley EC, Boura JA, Grines CL: Primary angioplasty versus intravenous thrombolytic therapy for acute myocardial infarction: a quantitative review of 23 randomized trials. Lancet 2003;361:13-20.

27 Szummer KE, Solomon SD, Velazquez EJ, et al: Heart failure on admission and the risk of stroke following acute myocardial infarction: the VALIANT registry. Eu Heart J 2005;26:2114-2119.

28 Andersen HR, Nielsen TT, Rasmussen K, et al: A comparison of coronary angioplasty with fibrinolytic therapy in acute myocardial infarction. N Engl J Med 2003;349:733742.

29 Pfeiffer MA, McMurray JJ, Velazquez EJ, et al: Valsartan, Captopril or both in myocardial infarction complicated by heart failure, left ventricular dysfunction or both. N Engl J Med 2003;349:1893-1906.

30 ISIS-2 collaborative group: Randomized trial of intravenous streptokinase, oral aspirin, both, or neither among 17,187 cases of suspected acute myocardial infarction: ISIS-2. J Am Coll Cardiol 1988;12(suppl 6):3A-13A.

31 CAPRIE Steering Committee: A randomised, blinded trial of clopidogrel versus aspirin in patients at risk of ischaemic events. Lancet 1996;348:1329-1339.

32 The CURE Investigators: Effects of clopidogrel in addition to aspirin in patients with acute coronary syndromes without ST-segment elevation. N Engl J Med 2001;345:494502.

33 Sabatine MS, Cannon CP, Gibson CM, et al: Addition of clopidogrel to aspirin and fibrinolytic therapy for myocardial infarction with ST elevation. N Engl J Med. 2005;352: 1179-1189.

34 Sabatine MS, Cannon CP, Gibson CM, et al: Effect of clopidogrel pretreatment before percutaneous coronary intervention in patients with ST-elevation myocardial infarction treated with fibrinolytics: the PCICLARITY study. JAMA 2005;294:12241232.

35 COMMIT collaborative group: Addition of clopidogrel to aspirin in 45,852 patients with acute myocardial infarction. Randomized placebo controlled trial. Lancet 2005;366: 1607-1621.

36 Beyth RJ, Quinn LM, Landefeld CS: Prospective evaluation of an index for predicting the risk of major bleeding in outpatients treated with warfarin. Am J Med 1998;105: 91-99.
37 Theroux P, Waters D, Lam J, et al: Reactivation of unstable angina after the discontinuation of heparin. N Engl J Med 1992;372:141145.

38 Van ES RF, Jonker JJC, Verheught FWA, et al: Aspirin and coumadin after acute coronary syndromes: a randomized, controlled trial, Lancet 2002:360:109-113.

- 39 Hurlen M, Abdelnoor M, Smith P, Erikssen J, Arnesen $\mathrm{H}$ : Warfarin, aspirin, or both after myocardial infarction, N Engl J Med 2002; 347:969-974.

40 CARS Investigators: Randomized doubleblind trial of fixed low-dose warfarin with aspirin after myocardial infarction. Lancet 1997;350:389-396.

41 Fiore LD, Ezekowitz MD, Brophy MT, et al: Department of Veterans Affairs Cooperative Studies Program clinical trial comparing combined warfarin and aspirin with aspirin alone in survivors of acute myocardial infarction: primary results of the CHAMP study. Circulation 2002;105:557-563.

42 Herlitz J, Holm J, Peterson M, et al: Factors associated with development of stroke longterm after myocardial infarction: experiences from the LoWASA trial. J Intern Med 2005;257:201-207.

43 Popma JJ, Ohman EM, Weitz J, et al: Antithrombotic therapy in patients undergoing percutaneous coronary intervention. Chest 2001:119(suppl 1):321S-336S

44 Leon MB, Baim DS, Popma JJ, et al: A clinical trial comparing 3 antithrombotic drug regimens after coronary artery stenting. Stent Anticoagulation Restenosis Study Investigators. N Engl J Med 1998;339:1665-1671.

45 Schomig A, Neumann FJ, Kastrati A, et al: A randomized comparison of antiplatelet and anticoagulant therapy after the placement of coronary artery stents. N Engl J Med 1996; 334:1084-1089.

46 Orford JL, Fasseas P, Melby S, et al: Safety and efficacy of aspirin, clopidogrel, and warfarin after coronary stent placement in patients with an indication for anticoagulation. Am Heart J 2004;147:463-467.

47 Mattichak SJ, Reed PS, Gallagher MJ, et al: Evaluation of safety of warfarin in combination with antiplatelet therapy for patients treated with coronary stents for acute myocardial infarction. J Interv Cardiol 2005;18: 163-166.

48 Buresly K, Eisenberg MJ, Zhang X, Pilote L: Bleeding complications associated with the combinations of aspirin, thienopyridine derivatives and warfarin in elderly patients following acute myocardial infarction. Arch intern Med 2005;165:784-789.

49 Berger PB, Bell MR: Safety and efficacy of ticlopidine for only 2 weeks after successful intracoronary stent placement. Circulation 1999;99:248-253. 
50 Rathore SS, Berger AK, Weinfurt KP, et al: Acute myocardial infarction complicated by atrial fibrillation in the elderly: prevalence and outcomes. Circulation 2000;101:969974.

-51 Pedersen OD, Abildstrom SZ, Ottesen MM, et al: Increased risk of sudden and non-sudden cardiovascular death in patients with atrial fibrillation/flutter following acute myocardial infarction. Eur Heart J 2006;27: 290-295.

-52 Pedersen OD, Bagger H, Kober L, Torp-Pedersen $\mathrm{C}$ : The occurrence and prognostic significance of atrial fibrillation/flutter following acute myocardial infarction. TRACE Study group. Eur Heart J 1999;20:748-754.

-53 Antman EM, Anbe DT, Armstrong PW, et al: ACC/AHA guidelines for the management of patients with ST elevation myocardial infarction. J Am Coll Cardiol 2004;44:671719.
54 Gage BF, Waterman AD, Shannon W, et al: Validation of clinical classification schemes for predicting stroke: results from the $\mathrm{Na}$ tional Registry of Atrial Fibrillation. JAMA 2001;285:2864-2870.

55 DiMarco JP, Flaker G, Waldo AL, et al: Factors affecting bleeding risk during anticoagulant therapy in patients with atrial fibrillation: Observations from the AFFIRM study. Am Heart J 2005;149:650-656.

-56 Fuster V, Ryden LE, Asinger RW, et al: ACC/ AHA/ESC guidelines for the management of patients with atrial fibrillation: Executive summary. Circulation 2001;104:2118-2150.

$\checkmark 57$ Albers GW, Amarenco P, Easton JD, et al: Antithrombotic and thrombolytic therapy for ischemic stroke: The seventh ACCP conference on Antithrombotic and Thrombolytic therapy. Chest 2004;126:483S-512S.
58 Van De Werf F, Ardissino D, Betriu A, et al: Management of acute myocardial infarction in patients presenting with ST-segment elevation. The Task Force on the Management of Acute Myocardial Infarction of the European Society of Cardiology. Eur Heart J 2003;24:28-66.

59 Staurt JC: Atrial Fibrillation Clopidogrel Trial with Irbesartan for Prevention of Vascular Events-Warfarin arm (ACTIVE)-W trial. Late-breaking clinical trials; Presented at AHA meeting, Dallas, 2005.

60 Stenestrand U, Lindback J, Wallentin L, et al: for the RIKS-HIA Registry. Anticoagulation therapy in atrial fibrillation in combination with acute myocardial infarction influences long-term outcome. Circulation 2005;112; 3225-3231.

61 Diener HC, Bogousslavsky J, Brass LM, et al: Aspirin and clopidogrel compared with clopidogrel alone after recent ischaemic stroke or transient ischaemic attack in highrisk patients (MATCH): randomized, double-blind, placebo-controlled trial. Lancet 2004;364:331-337. 